\title{
Ultrasound Guided Steroids Injection for Carpal Tunnel Syndrome
}

\author{
Naglaa Dabees ${ }^{1}$, Hanan El-Saadany ${ }^{2}$, Aly El-Barbary ${ }^{1}$, Al-Shimaa Ammar ${ }^{1}$ \\ ${ }^{1}$ Radiodiagnosis Departments, Faculty of Medicine, Tanta University, Tanta, Egypt \\ ${ }^{2}$ Physical Medicine Departments, Faculty of Medicine, Tanta University, Tanta, Egypt
}

\section{Email address:}

naglaadabees@live.com (N. Dabees), hanan0777@hotmail.com (H. El-Saadany), sweet_dr-shimaa@yahoo.com (Al-Shimaa A.), aly.elbarbary@yahoo.cm (A. El-Barbary)

\section{To cite this article:}

Naglaa Dabees, Hanan El-Saadany, Aly El-Barbary, Al-Shimaa Ammar. Ultrasound Guided Steroids Injection for Carpal Tunnel Syndrome. International Journal of Medical Imaging. Vol. 3, No. 4, 2015, pp. 75-81. doi: 10.11648/j.ijmi.20150304.12

\begin{abstract}
Objective: The aim of this work was to evaluate the role of ultrasound-guided steroids injection for carpal tunnel syndrome (CTS). Study design: This is a prospective study done on thirty patients with carpal tunnel syndrome with mild to moderate severity. Patients were divided into two groups; group I of fifteen patients 'wrists injected by steroids using ultrasound guidance and group II of another fifteen patients injected blindly- as control- with the same material .Results: There was significant improvement in symptoms and ultrasound findings, after steroid injection, in both groups, being more in group I than group II, with shorter average time to symptom relief, in group I than group II. Moreover, the complications were significantly lower in group I than group II. Conclusions: Ultrasound guided steroids injection is more effective in reducing the symptoms and improving function of CTS with lower risk of nerve injury than blind local steroid injection.
\end{abstract}

Keywords: Ultrasound, Steroids Injection, Carpal Tunnel Syndrome

\section{Introduction}

Carpal tunnel syndrome (CTS) is one of the most common entrapment neuropathy syndromes of the upper limb ${ }^{(1,2)}$.

Its incidence is $139 / 100,000$ per year for men and $506 / 100,000$ per year for women. ${ }^{(3)}$

Carpal tunnel syndrome (CTS) occurs at a rate of 5.2 per 10,000 full time workers, and this syndrome requires the longest re-occupational period of all conditions that result in lost work days, with a median of 30 days lost. ${ }^{(4)}$

It arises from entrapment of the median nerve at the wrist; typically the disorder is characterized by numbness or tingling in the sensory distribution of the nerve in the hand, which may be accompanied by pain and or weakness of the muscles of the thumb ${ }^{(5)}$.

Women between the ages of 45-60 years suffer from CTS more than men with a ratio of $3: 1^{(6)}$.

Generally, accepted treatments include: steroids injected locally, splinting, and surgical release of the transverse carpal ligament ${ }^{(7)}$. Steroid injection into the carpal tunnel is frequently used and is known to be effective in the treatment of CTS. ${ }^{(8,9,10)}$

In daily clinical practice, this intervention is often performed blindly, with risk of damaging the median nerve and the surrounding vulnerable structures such as tendons and vessels. $(11,12,13,14)$

To improve accuracy of the intervention, image-guided injections are required. Because ultrasound is none ionizing, readily available, relatively oflow cost, and easily accepted by patients, it has become the first choice to guide carpal tunnel injections. Moreover, ultrasound provides a real-time anatomic high-resolution image of the median nerve, the carpal tunnel, and the neighboring structures and assists the diagnosis as well as the suggestion of an etiology ${ }^{(13)}$.

The real-time capability of ultrasound provides a clear advantage in guiding carpal tunnel injections because it enables visualizing the needle tip continuously and ensures that the needle is placed precisely in the desired location, avoiding the risk for inadvertent nerve and surrounding structure damage ${ }^{(13,14)}$.

\section{Aim of the Work}

The aim of this work was to evaluate the role of ultrasound-guided steroids injection for treating carpal tunnel syndrome. 


\section{Patients and Methods}

\subsection{Patients}

This study was conducted on thirty patients with idiopathic CTS diagnosed by clinical examination, electrophysiological study, and ultrasound. Patients were referred from the departments of physical medicine and rheumatology, to the department of Diagnostic Radiology and Medical Imaging, at Tanta University Hospital, during the period from 12/2013 to $11 / 2014$.

They were twenty six females $(86.7 \%)$ and four males $(13.3 \%)$ with age range from 20 - 60 years and a mean age of 40 years.

\subsubsection{Inclusion Criteria}

Patients with mild to moderate symptoms of carpal tunnel syndrome, who failed responding to other methods of treatment and / or those refused surgery.

\subsubsection{Exclusion Criteria}

Male and female Patients with Parkinsonism, traumatic nerve injury, previous steroids injection in the same wrist and other causes of neuropathy rather than CTS.

\subsubsection{Study Design}

It is a prospective study done on thirty patients with carpal tunnel syndrome with mild to moderate severity. Patients were divided into two groups; group I of fifteen patients whose wrists were injected with steroids under ultrasound guidance and group II of another fifteen patients injected blindly- as control- with the same material

All patients were subjected to full history taking, clinical examination and laboratory investigations.

Electrophysiological studies were done pre and post (after 6 weeks of injection) to all patients in both groups. Studies included motor and sensory nerve conduction as well as $\mathrm{F}$ wave for both median and ulnar nerves.

Assessment of all patients in both groups pre and post injection (after 6 weeks of injection) was then done by Boston Carpal tunnel questionnaire (BCTQ). Also, Ultrasound examination was done to all patients pre and post (6 weeks after injection) injection in both group, to assess the median nerve and flexor retinaculum.

All patients were examined at Radiology Department, Tanta university hospital, using "biomedical P-K" US machine. The status of CTS was evaluated pre and post steroid injection, considering the following parameters: cross surface area (CSA) of median nerve, ratio between major and minor axis of median nerve at distal carpal tunnel, and finally thickness and bowing of flexor retinaculum (FR).

\subsection{Methods}

\subsubsection{US- Guided Steroid Injection Technique}

Before injection, the patient was seated, with the forearm supinated and the wrist slightly dorsiflexed. Ultrasound-guided steroids injection of carpal tunnel syndrome was done using 26 gauge needle to minimize discomfort. After obtaining skin anesthesia with a vapocoolant spray, the needle was passed into the skin on the ulnar side of the proximal carpal tunnel at the level of the distal wrist crease. The needle was passed superficial to the ulnar nerve and artery, penetrating the FR on the ulnar side of the carpal tunnel.

With ultrasound guidance, the needle was directed to the superficial ulnar side of the median nerve, after which a portion of the injectate was delivered. As the injectate was delivered, the median nerve typically peeled off the undersurface of the FR, allowing the needle to be advanced between the nerve and the overlying retinaculum.

The needle was then withdrawn to the ulnar side of the median nerve and redirected to the deep side of the ulnar portion of the nerve. Under real-time visualization, additional injectate was delivered, separating the nerve from the underlying sub synovial connective tissue.

In this manner, the nerve was completely surrounded with the injectate and mechanically separated from the potentially constricting surrounding connective tissues. Finally, the needle was directed yet deeper into the sub synovial connective tissue, where the remainder of the injectate was delivered.

A typical injectate consists of $1 \mathrm{ml}$ of $40-\mathrm{mg} / \mathrm{mL}$ methylprednisolone acetate (Depo- Medrol 40mg/ml) and 1 $\mathrm{mL}$ of $1 \%$ lidocaine, delivered in equal portions above the nerve, below the nerve, and into the subsynovial connective tissue. After completion of the injection, the distal carpal tunnel is scanned to ensure injectate distribution throughout the distal extent of the carpal tunnel.

\subsubsection{The Blind Injection Technique}

The Blind Injection Technique was conducted using the ulnar approach; the wrist was positioned in 30 degrees dorsiflexion resting on a towel roll. The injection sites were either the proximal wrist crease or ulnar side marked by Palmaris longus tendon or wrist midline if Palmaris longus is absent.

Under aseptic measures, needle was inserted and aimed 30-45 degrees distally toward middle-ring finger. Insertion was done for 1-2 cm until no resistance was encountered. Injection was stopped once parasthesia developed. The injected material used in the blind injection technique was the same as in the ultrasound- guided technique.

Local compression at the site of injection was applied to all patients in both groups to allow proper absorption of the injected steroid and to minimize any possibility for occurrence of hematoma. Analgesics was given to relieve the pain.

\subsubsection{Follow $U p$}

Follow up was done at the base line and after 6 weeks by:

I. clinical evaluation using BCTQ score, the latter evaluates symptomatic severity and function recovery with a score of 0-5 according to severity of symptoms or difficulty in a certain activity, the worse the symptoms, the higher the score.

II. Ultrasound of volar wrist, evaluating:

a. Cross surface area of median nerve ( $\mathrm{N}$ up to $10 \mathrm{~mm} 2$ )

b. Ratio between major to minor axis of median nerve ( $\mathrm{N}$ up to 3 ) 
c. Flexor retinaculum thickening ( $\mathrm{N}$ less than $4 \mathrm{~mm}$ )

III. Electrophysiological studies including, motor and sensory nerve conduction and $\mathrm{F}$ wave of median and ulnar nerves.

\subsection{Statistics Analysis}

Statistical analysis was done, using the mean, standard error, student t- test, Chi-square and Wilcoxon Signed Ranks Test, tests by SPSS V17.

\section{Results}

This study was conducted on thirty patients with carpal tunnel syndrome with mild to moderate severity. Patients were divided into two groups; group I of fifteen patients whose 'wrists were injected with steroids under ultrasound guidance and group II of another fifteen patients injected blindly- as control- with the same material.

They were twenty six females $(86.7 \%)$ and four males $(13.3 \%)$ with age range from 20 - 60 years and mean age of 40 years.

Table (1). The improvement of symptomatic severity and functional evaluation by BCTQ in both groups before and after steroids injection.

\begin{tabular}{|c|c|c|c|c|c|c|c|c|c|c|c|c|}
\hline & & \multicolumn{2}{|c|}{ Normal } & \multicolumn{2}{|c|}{ Mild } & \multicolumn{2}{|c|}{ Mild to moderate } & \multicolumn{2}{|c|}{ moderate } & \multirow{2}{*}{ Total } & \multirow{2}{*}{ P. value } & \multirow{2}{*}{$\%$ of improvement } \\
\hline & & $\mathbf{N}$ & $\%$ & $\mathbf{N}$ & $\%$ & $\mathbf{N}$ & $\%$ & $\mathbf{N}$ & $\%$ & & & \\
\hline \multirow{2}{*}{ G I } & Pre & - & - & - & - & 8 & 53.33 & 7 & 46.67 & 15 & \multirow{2}{*}{$0.002 *$} & \multirow{2}{*}{$86.66 \%$} \\
\hline & Post & 8 & 53.33 & 5 & 33.33 & 1 & 6.67 & 1 & 6.67 & 15 & & \\
\hline \multirow{2}{*}{ G II } & Pre & - & - & - & - & 7 & 46.67 & 8 & 53.33 & 15 & \multirow{2}{*}{0.252} & \multirow{2}{*}{$53.33 \%$} \\
\hline & Post & 2 & 13.33 & 5 & 33.33 & 2 & 13.33 & 6 & 40.01 & 15 & & \\
\hline
\end{tabular}
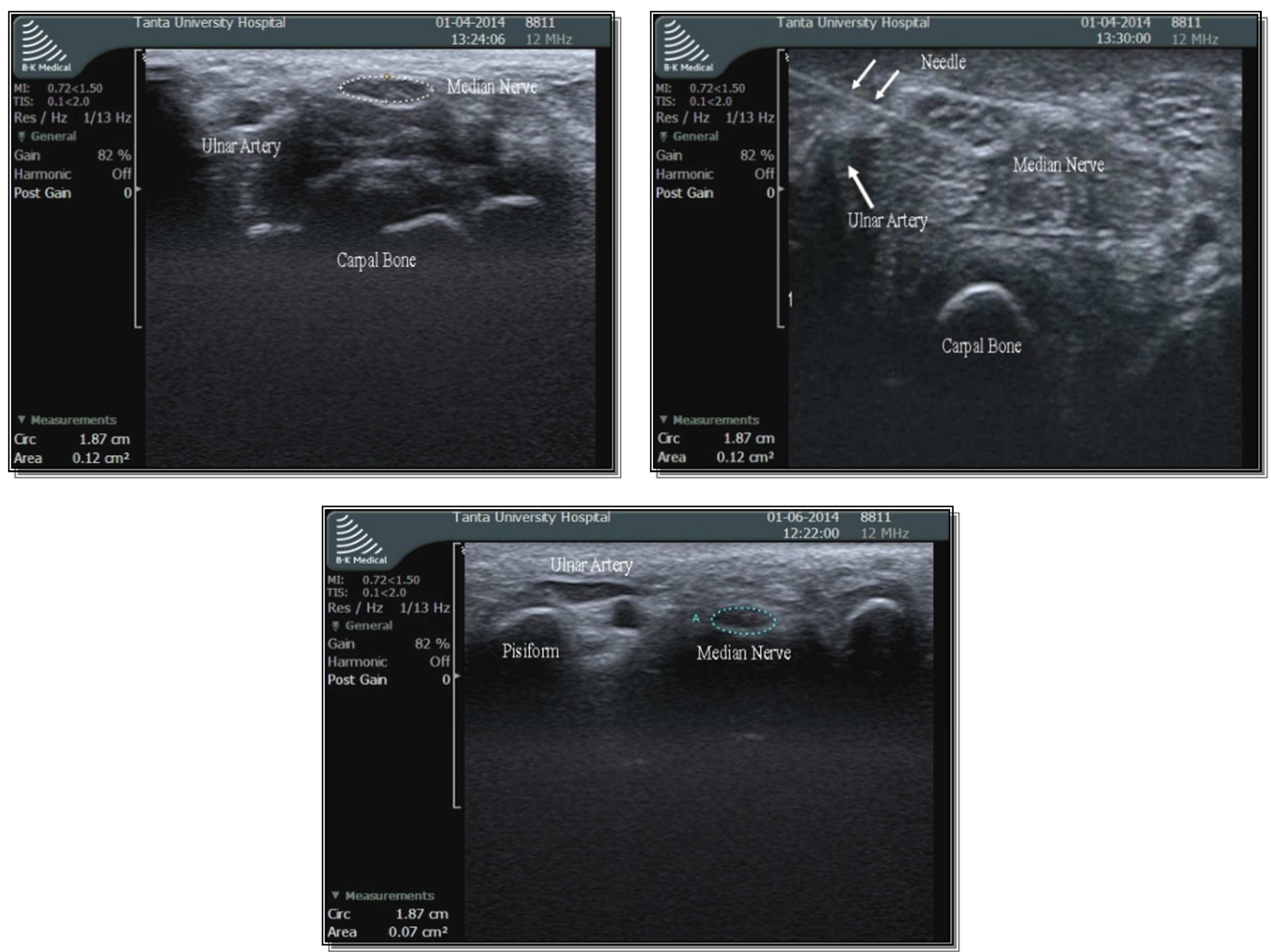

Fig. 1. a) US image of a patients wrist with mild to moderate CTS showing swelling of the median nerve (CSA=12mm2),b) US image of carpal tunnel injection, the needle is seen as a white line. C) US image after 6 weeks follow up showing decreased swelling of the median nerve (CSA=7mm2).
In both groups, pain was the commonest symptom (100\%), followed by parasthesia, hyposethesia, hand weakness and pain awakening patient from sleep. After steroid injection symptoms improvement was encountered in both groups. Pain improved in $80 \%$ of group I, four days after injection compared to $63.33 \%$ of group II, seven days after injection with statistically significant difference. Again, pain that awakened patient from sleep, was improved in $83.3 \%$ of group I vs. $52 \%$ of group II. Hand weakness was surprisingly improved in $100 \%$ of group I vs. 66.6 in group II. Parasthesia as well as hypoesthesia, had also improved in both groups, more with US guided injection, than with blind injection.

Table (1) shows significant improvement $(\mathrm{p}=0.002)$ of severity of symptoms and function by BCTQ after steroid injection in group I. Mild to moderate and moderate severity of the fifteen cases, before injection, became normal in 8 cases and mild in 5cases, while severity persists as mild to moderate in one case ,and moderate in one case, with total improvement of $86.66 \%$. However, in group II severity persists as mild to moderate in 2 cases and moderate in 6 cases with total improvement of $53.33 \%(\mathrm{p}=0.252)$. 
The ultrasound findings of the two studied groups before steroids injection (table 2) included 1) Swelling of the median nerve $<10 \mathrm{~mm}^{2}(86.67 \%)$ in group I vs. $(66.67 \%)$ in group II, at the proximal carpal tunnel (commonest), followed by 2) Hypoechgenic appearance of the median nerve $(80 \%)$ in group I vs. $(46.67 \%)$ in group II 3)Flattening of the median nerve at the distal carpal tunnel (20\%) in group I vs. (26.6\%) in group II 4)Thickening and bowing of the FR $(40 \%)$ in group I vs. $(53.33 \%)$ in group II. The ultrasound findings of the diseased wrists, before injection, (table 2), had improved significantly, after steroids injection (table 3 ). The median nerve cross surface area (CSA), had dramatically been reduced, in $92 \%$ of group I, and $69.77 \%$ in group II. Moreover, the median nerve regained its normal ecchogenicity, in $100 \%$ of group I vs. $84 \%$ of group II. The flattening of the median nerve had been relieved in $66 \%$ of group I, and in $57 \%$ of group II. The thickness of FR, had returned to normal in $83 \%$ of group I, vs. 57.5 of group II.

Table (2). The US findings of the studied wrists of both groups before steroids injection.

\begin{tabular}{|c|c|c|c|c|c|c|}
\hline \multirow{2}{*}{ US finding of carpal tunnel syndrome } & \multicolumn{2}{|c|}{ Group I } & \multicolumn{2}{|c|}{ Group II } & \multicolumn{2}{|c|}{ Total } \\
\hline & $\mathbf{N}$ & $\%$ & $\mathbf{N}$ & $\%$ & $\mathbf{N}$ & $\%$ \\
\hline Swelling of the median nerve $<10 \mathrm{~mm} 2$ at the proximal carpal tunnel & 13 & 86.67 & 10 & 66.67 & 23 & 76.67 \\
\hline Hypoechgenic appearance of median nerve & 12 & 80.00 & 7 & 46.67 & 19 & 63.33 \\
\hline Flattening of the median nerve at the distal carpal tunnel & 3 & 20.00 & 4 & 26.67 & 7 & 23.33 \\
\hline Thickening and bowing of the FR & 6 & 40.00 & 8 & 53.33 & 14 & 46.67 \\
\hline
\end{tabular}

(NB: Some patient's writs showed more than one US finding)

Table (3). The ultrasound findings in group I and II wrists after steroids injection.

\begin{tabular}{|c|c|c|c|c|c|c|c|c|}
\hline \multirow{2}{*}{ Post } & \multicolumn{2}{|c|}{ Group I } & \multicolumn{2}{|c|}{ Group II } & \multicolumn{2}{|l|}{ Total } & \multicolumn{2}{|c|}{ Chi-square } \\
\hline & $\mathbf{N}$ & $\%$ & $\mathbf{N}$ & $\%$ & $\mathbf{N}$ & $\%$ & $\mathbf{X} 2$ & P-value \\
\hline Reduced diameter of median nerve less than $10 \mathrm{~mm}^{2}$ & $12 / 13$. & 92.31 & $4 / 10$ & 40.00 & $16 / 23$ & 69.57 & 7.304 & $0.007 *$ \\
\hline Normal echogencity of median nerve & $12 / 12$ & 100.00 & $4 / 7$ & 57.14 & $16 / 19$ & 84.21 & 6.107 & $0.013^{*}$ \\
\hline Relieved flattening and return to normal axis & $2 / 3$ & 66.67 & $2 / 4$ & 50.00 & $4 / 7$. & 57.14 & 0.194 & 0.659 \\
\hline Returned of normal thickness of FR & $5 / 6$ & 83.33 & $3 / 8$ & 37.50 & $8 / 14$ & 57.14 & 3.13 & $0.044^{*}$ \\
\hline
\end{tabular}

(NB: Some patient show more than one US finding)
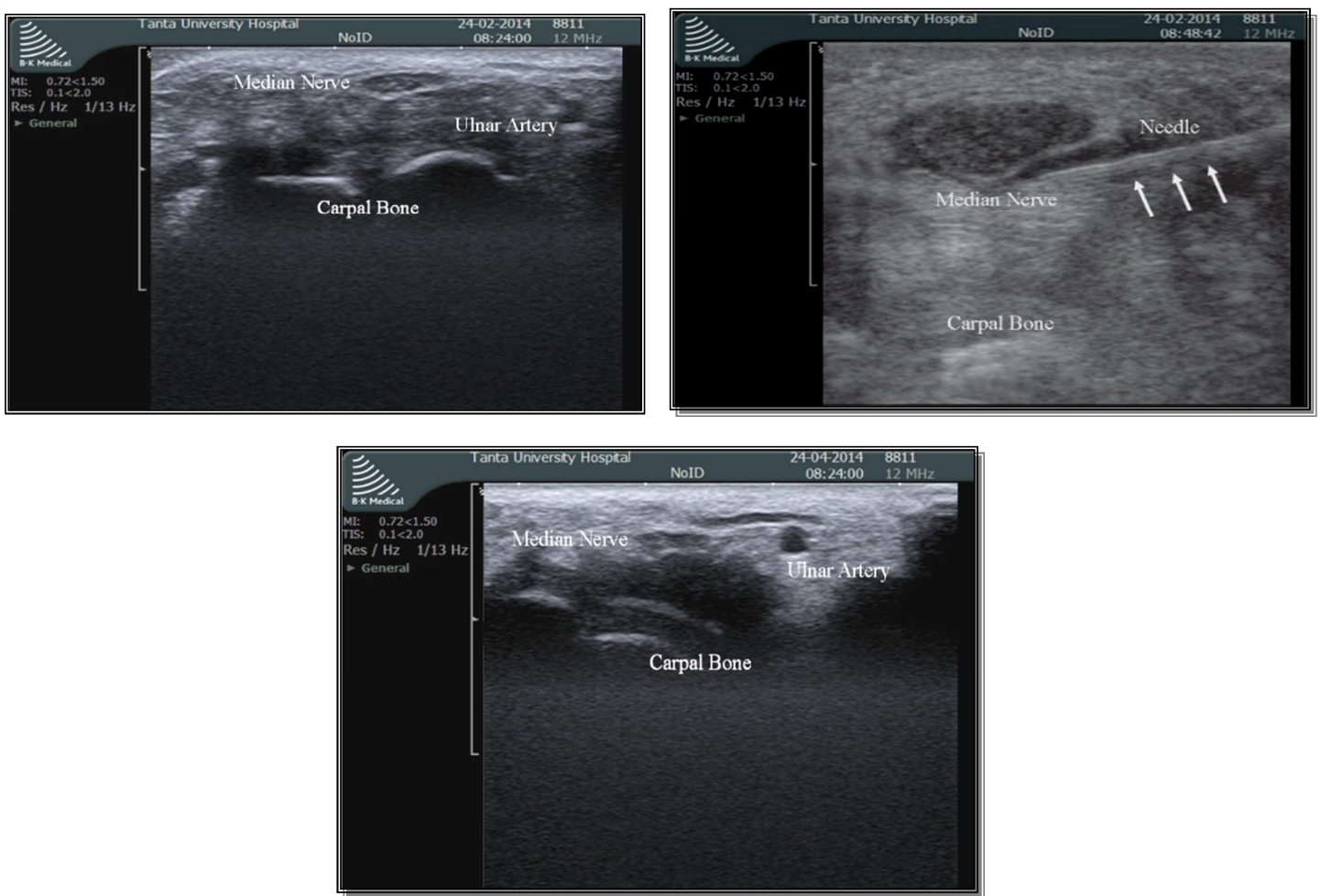

Fig. 2. a) US image of a female patients wrist with moderate CTS showing swelling of the median nerve (CSA=13mm2),b) US image of carpal tunnel injection, the needle is seen as a white line. C) after 6 weeks follow up US image shows decreased swelling of the median nerve (CSA=8mm2). 
The electrophysiological findings of the thirty wrists before steroids injection in both groups ranged from mild to moderate. After steroids injection (table 4), the following electrophysiological changes were encountered ; In group I, out of the seven cases with moderate CTS, 2 cases became normal, 4 cases became mild, and one case showed no changes. While, out of 8 cases with mild CTS, 7cases became normal, and one case didn't change.

In group II, out of 8 cases with moderate CTS, one case became normal, four case became mild, and 3 cases remained unchanged. There were 7 cases in group II suffering from mild to CTS, out of these, 2 cases became normal, and 5 cases didn't respond.

Post injection complication in both blind and ultrasound guided technique were summarized in (table 5). Pain, oedema and tingling, although had occurred in both groups, however, they were significally lower in group I compared to group II.

Table (4). Electrophysiological changes of CTs before and after steroids injection in both groups.

\begin{tabular}{|c|c|c|c|c|c|}
\hline \multirow{2}{*}{ Before } & \multirow{2}{*}{ After } & \multicolumn{2}{|c|}{ Group I } & \multicolumn{2}{|c|}{ Group II } \\
\hline & & Ratio & $\%$ & No & $\%$ \\
\hline \multirow{4}{*}{$\begin{array}{l}\text { Moderate CTS } \\
7 \text { cases (group I) } \\
8 \text { cases (group II) }\end{array}$} & Normal & $2 / 7$ & 28.6 & $1 / 8$ & 12.5 \\
\hline & Mild & $3 / 7$ & 42.8 & $1 / 8$ & 12.5 \\
\hline & Mild to moderate & $1 / 7$ & 14.3 & $3 / 8$ & 37.5 \\
\hline & No changes & $1 / 7$ & 14.3 & $3 / 8$ & 37.5 \\
\hline Mild to moderate CTS & Normal & - & - & $2 / 7$ & 28.6 \\
\hline 7cases (group II) & No change & $1 / 4$ & $25 \%$ & $2 / 7$ & 28.6 \\
\hline $\begin{array}{l}\text { Mild CTS } \\
4 \text { cases (group I) }\end{array}$ & Normal & $4 / 4$ & 100 & - & - \\
\hline Total & & 15 & & 15 & \\
\hline
\end{tabular}

Table (5). Post injection complications in both groups.

\begin{tabular}{|c|c|c|c|c|c|c|c|c|}
\hline \multirow{2}{*}{ Complications } & \multicolumn{2}{|c|}{ Group I } & \multicolumn{2}{|c|}{ Group II } & \multicolumn{2}{|c|}{ Total } & \multicolumn{2}{|c|}{ Chi-square } \\
\hline & $\mathbf{N}$ & $\%$ & $\mathbf{N}$ & $\%$ & $\mathbf{N}$ & $\%$ & $\mathbf{X} 2$ & P-value \\
\hline Pain & 3 & 20.00 & 8 & 53.33 & 11 & 36.67 & 3.589 & $0.05 *$ \\
\hline Tingling & 1 & 6.67 & 6 & 40.00 & 6 & 20 & 2.981 & 0.084 \\
\hline
\end{tabular}
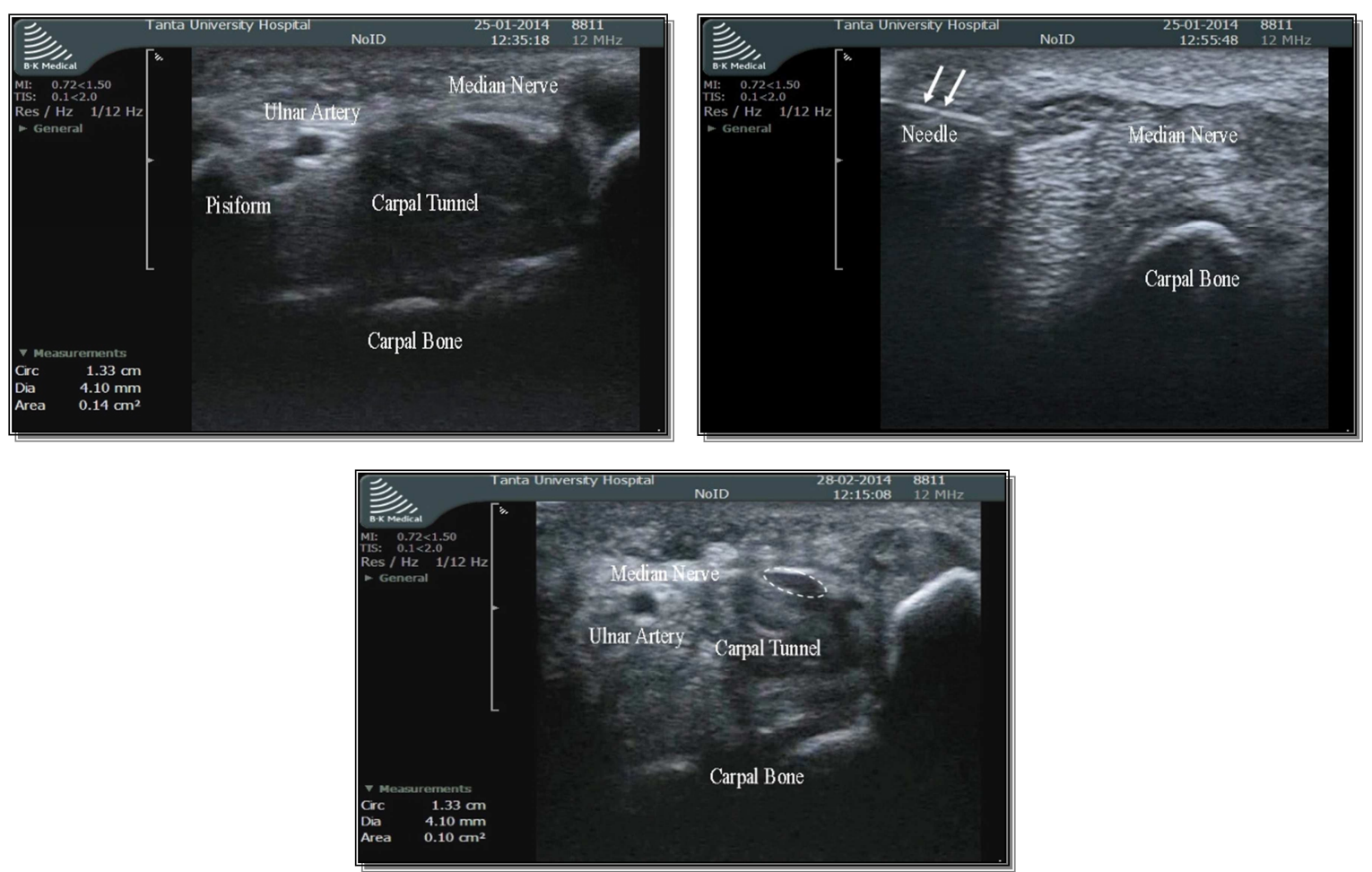

Fig. 3. a) US image of a female patients wrist with moderate CTS showing swelling of the median nerve (CSA=14mm2), b) US image of carpal tunnel injection, the needle is seen as a white line. C) after 6 weeks follow up US image shows decreased swelling of the median nerve (CSA=10mm2). 


\section{Discussion}

Treatment of idiopathic CTS ranges from conservative management and /or corticosteroid injection to surgical decompression depending on the degree and the duration of symptoms and etiology of the disease. ${ }^{(15)}$

Thirty patients with idiopathic CTS were included in our study. There were 26 females $(86.7 \%)$ and 4 males $(13.3 \%)$, aging from 20-60 years, with mean of 40 years this agrees Aygul et al., $2005^{(16)}$ which means that CTS is a disease of the middle age.

Pain along the median nerve distribution was present in all patients $(100 \%)$ and this coincided with Lee et al., 2009 who reported that all patients with symptoms of CTS suffered from pain along distribution of the median nerve.$^{(17)}$

After treatment, there was an improvement in the mean values of the degrees of pain in the two studied groups. The improvement of the degrees of pain in group I, II was significant after injection and at follow up as compared to before injection in both groups. This agreed with the study done by Karatay et al., $2009^{(18)}$ who had treated forty five patients with bilateral CTS. The patients were divided into 2 groups; group 1 injected locally by $4 \mathrm{mg}$ of dexamethasone US- guided and group II injected blindly. They found significant improvement in the degree of pain in group 1, II after one month of treatment and it remained significant at six month follow up in both groups.

In this study, there was improvement of the median nerve ultrasound findings in both groups, group I is much better (Table 3) due to proper visualization of the nerve. The swelling of the median nerve was reduced in 12 out of 13 wrists $(92.31 \%)$. Return of the median nerve to its normal axis occurred in 2 out of 3 wrists $(66.67 \%)$. Thickening of FR was reduced to normal in 5 out of 6 wrists $(83 \%)$ and echogenic pattern of median nerve returned to normal in all cases.

The improvement of median nerve condition by US examination in group I was better than group II. This was in accordance with Ustun et al., 2013 ${ }^{(19)}$ who reported better improvement of the median nerve conditions in the USguided group at 12 weeks after steroids injection.

As regard BCTQ, there was significant improvement of symptoms and functional score in group I more than group II six weeks after injection ( $\mathrm{P}$ value $=0.049$ ) and this partially agrees with Ustun et al., $2013^{(19)}$ who reported significantly improved scores in each group at six weeks after treatment (all P G 0.05), at 12 weeks after treatment, the improvement in symptom severity scores in the US-guided group was better than in the blind injection group (P G 0.05).

In our study both US- guided and blind steroid injections were effective in reducing the symptoms of CTS and improving the function. However, earlier onset with better improvement of symptom was detected in the US- guided group and this represented by improvement of pain in 12 out of 15 wrists $(80 \%)$ compared to 7 out of 15 wrists in group II
(46.67\%). Pain was relieved 4 days after injection in group I and after 7 days in group II ,this in accordance with Ustun et al., $2013^{(19)}$ who showed that symptoms were relieved $4.11 \pm$ 3.25 days after injection in the US-guided group, vs. $6.23 \pm$ 3.54 days in the blind injection group.

Major complications as median nerve injury did not occur in both groups with more accuracy of US- guided technique due to proper visualization of median nerve under real time US. This agrees with Racasan and Dubert, $200{ }^{(20)}$ who reported minimal damage of the median nerve under real time US- guided injection and blinded injection technique.

Minor complications were reported at this study (Table 4), Pain, oedema and tingling, though had occurred in both groups, however, they were significally lower in group I compared to group II. This is in accordance with Ustun et al., $2013^{(19)}$ who reported that pain was less with US-guided than blind technique.

\section{Conclusions}

Ultrasound guided steroids injection is more effective in reducing the symptoms and improving the function of CTS with lower risk of nerve injury than blind local steroid injection.

\section{References}

[1] Klauser AS, Halpern E J, Faschingbauer R, et al. (2011): Blind median nerve in carpal tunnel syndrome: assessment with US cross-sectional area measurement. Radiology; 259:808-815.

[2] Demircay E, Civelek E, Cansever T, et al. (2011): Anatomic variations of the median nerve in the carpal tunnel: a brief review of the literature. Turk Neurosurg; 21: 388-396

[3] Bland JD. (2001): Do nerve conduction studies predict the outcome of carpal tunnel compression? Muscle Nerve; 24: 935-40.

[4] Kim J, Kim J, Son J, et al. (2004): Prevalence of carpal tunnel syndrome in meat and fish processing plants. J Occup Health; 46: $230-4$

[5] Claes F, Verhagen W and Meulstee J. (2007): Current practice in the use of nerve conduction studies in carpal tunnel syndrome by surgeons in the Netherlands. J Hand SurgEur; 32E:663-667.

[6] Luckhaupt SE, Dahlhamer JM, Ward BW, et al. (2013): Prevalence and work-relatedness of carpal tunnel syndrome in the working population, United States, 2010 national health interview survey. Am J Ind Med 56 : 615-624.

[7] Piazzini DB, Aprile I, Ferrara PE, et al. (2007): A systematic review of conservative treatment of carpal tunnel syndrome. Clin Rehabil 21: 299-314.

[8] Karadas O, Tok F, Akarsu S, et al. (2012): Triamcinolone acetonidevs procaine hydrochloride injection in the management of carpal tunnel syndrome: Randomized placebocontrolled study. J Rehabil Med; 44:601-604 
[9] Karadas O, Oma K, Tok F, et al (2012): Effects of steroid with repetitive procaine $\mathrm{HCl}$ injection in the management of carpal tunnel syndrome: An ultrasonographic study. J NeurolSci; 316:76-78

[10] Karadas O, Tok F, Ulas UH, et al. (2011): The effectiveness of triamcinolone acetonide vs. procaine hydrochloride injection in the management of carpal tunnel syndrome: A double-blind randomized clinical trial. Am J Phys Med Rehabil; 90:287-292

[11] Kara M, zoakar L, De Muynck M, et al (2012): Musculoskeletal ultrasound for peripheral nerve lesions. Eur J PhysRehabil Med; 48:665-674

[12] Ulasli AM, Duymus M, Nacir B, et al. (2013): Reasons for using swelling ratio in sonographic diagnosis of carpal tunnel syndrome and a reliable method for its calculation. Muscle Nerve; 47:396-402.

[13] De Muynck M, Parlevliet T, De Cock K, et al. (2012): Musculoskeletal ultrasound for interventional physiatry. Eur J Phys Rehabil Med; 48:675-687.

[14] Tagliafico A, Bodner G, Rosenberg I, et al. (2010): Peripheral nerves: Ultrasound-guided interventional procedures. Semin Musculoskelet Radiol; 14:514-559.

[15] Aganval V, Singh R, Sachdev A, et al. (2005): A prospective study of the long-term efficacy of local methyl prednisolone acetate injection hi the management of mild carpal tunnel syndrome. Rheumatology; 44:647-650.

[16] Aygul R, Ulvi H, Karatay S, et al. (2005): Determination of sensitive electrophysiologic parameters at follow-up of different steroid treatments of carpal tunnel syndrome. J Clin Neurophysiol.; 22 :222-230.

[17] 152. Lee JH, An JH, Lee SH, et al. (2009): Effectiveness of Steroid Injection in Treating Patients With Moderate and Severe Degree of Carpal Tunnel Syndrome Measured by Clinical and Electrodiagnostic Assessment. Clin J Pain; 25:111-115.

[18] 156. Karatay S, Aygul R, Alkan M, et al. (2009): The comparison of phonophoresis, iontophoresis and local steroid injection in carpal tunnel syndrome treatment. Joint Bone Spine; 55:156-157.

[19] 135. Ustun N, Tok F, Yagiz AE et al (2013): Ultrasoundguided vs. blind steroid injections in carpal tunnel syndrome: a single-blind randomized prospective study. Am J Phys Med Rehabil; 92:999-1004.

[20] 157. Racasan O and Dubert T. (2005): The safest location for steroid injection in the treatment of carpal tunnel syndrome. J Hand Surg Br: 30; 412-414. 